\title{
BURNOUT, WORK ENGAGEMENT AND SENSE OF COHERENCE IN FEMALE ACADEMICS in higher-EDUCATION institutions in SoUth Africa
}

\section{Authors:}

Adéle Bezuidenhout ${ }^{1}$

Frans V.N. Cilliers ${ }^{2}$

\section{Affiliations:}

${ }^{1}$ Department of People

Management and

Development, Tshwane

University of Technology,

South Africa

${ }^{2}$ Department of Industrial and Organisational

Psychology, Unisa,

South Africa

Correspondence to:

Adéle Bezuidenhout

email:

bezuidenhouta@tut.ac.za

\section{Postal address:}

Department of People

Management and

Development, Faculty of

Management Sciences,

Private Bag X680, Pretoria

0001, South Africa

\section{Keywords:}

salutogenic paradigm;

positive psychology; work wellness

\section{Dates:}

Received: 24 Oct. 2009

Accepted: 21 June 2010

Published: 19 Nov. 2010

How to cite this article: Bezuidenhout, A., \& Cilliers, F.V.N. (2010). Burnout, work engagement and sense of coherence in female academics in higher-education institutions in South Africa. SA Journal of Industrial Psychology/SA

Tydskrif vir Bedryfsielkunde, 36(1), Art. \#872, 10 pages. DOI: 10.4102/sajip.v36i1.872

This article is available

http://www.sajip.co.za

(C) 2010. The Authors. Licensee: OpenJournals Publishing. This work is licensed under the Creative Commons Attribution License.

\section{ABSTRACT}

Orientation: Female academics in higher-education institutions face numerous challenges in the continuously changing landscape of South African higher education. Mergers, increasing job demands, ever-increasing class sizes and role conflict inherent in the female role contribute extensively to the manifestation of stress and burnout in this population group.

Research purpose: This research was conducted from a salutogenic paradigm, seeking to find ways of avoiding the negative consequences of burnout and contributing towards the positive experience of work engagement for the female academic. The research also explored the effect of the individual academic's sense of coherence (SOC) on her experience of burnout and work engagement.

Research design, approach and method: The research was quantitative in nature. A psychometric instrument was sent to all the permanently employed female academics at Unisa and Tshwane University of Technology (TUT), measuring their levels of burnout, work engagement and SOC. The completed questionnaires were statistically analysed.

Main findings: The findings included average levels of burnout, with definite signs that the experience of burnout is on the increase. The cynicism sub-dimension of burnout showed increased levels, work engagement scores were just above average and SOC scores were low.

Practical/managerial implications: This article offers a psychological interpretation of the variables in the target group. The article contributes towards the body of research studies conducted from a positive psychological paradigm and, specifically, on the female gender.

Contribution/value-add: The main recommendations are that university management needs to take cognisance of the alarming symptoms of burnout present in the population under discussion. Strategies are recommended to address these and to nurture work engagement.

\section{INTRODUCTION}

The metaphor of a 'leaking pipeline' was used by De la Rey (2008) to refer to the way in which highereducation institutions fail to find ways to retain female academics; the theme of the conference organised by Higher Education Resource Services-South Africa at the University of Cape Town, where De la Rey delivered her address, was 'Institutional cultures and higher-education leadership: Where are the women?' UNESCO (2009) also argued that, worldwide, more females are needed in higher education.

In South Africa, academics are pressed to produce more research outputs, lecture bigger classes and supervise more postgraduate students. The heavier workloads, with less support and fewer means, require more time and energy.

Female academics, specifically, are likely to get fewer rewards and less recognition for their work and to face numerous challenges in the highly dynamic kaleidoscope of South African higher education. Role conflict, institutional mergers and poor literacy and numeracy levels among first-year students contribute to the manifestation of burnout in this population group. The poor literacy and numeracy levels (a negative learner profile) of learners also manifest as a significant contributor to burnout among secondary educators in South Africa (Van Tonder \& Williams, 2009).

Lease (1999) reported that female academics find it difficult to make sense of organisational structures and of the values of the universities that employ them. Understanding the expectations of performance and advancement and coping with conflicting demands on their time are highly stressful. A lower academic rank, often occupied by female academics, is also associated with more stressful experiences.

Van den Broeck, Vansteenkiste, De Witte and Lens (2008) concluded that, for a job to be health promoting, it should be designed in such a way that exhaustion (a core component of burnout and often manifested in academic populations) is avoided and that vigour (a core component of work engagement) is facilitated.

Strümpfer and De Bruin (2009) conducted a meta-analysis on South African data in terms of sense of coherence (SOC) and job satisfaction $(N=3446)$. The results provided strong support for the fact that SOC correlates with job satisfaction.

The possible moderating effect of the individual female academic's SOC on her experience of burnout and work engagement in the institution of higher education is explored in this article. Focus is specifically on the positive experience of work engagement in the sample of female academics under discussion.

It is a well-investigated, confirmed and documented fact that burnout is a reality among academics (Barkhuizen, Rothmann \& Tytherleigh, 2004; Burke \& Greenglass, 1995; Tytherleigh, 2003). Burnout 
among female academics, specifically, however, has not been studied in South Africa. Moreover, the work experience of female academics from a positive psychological and salutogenic paradigm, investigating their SOC and the work engagement that they experience, has not yet been the focus of organisational and industrial-psychology researchers.

The unique contribution of this study therefore lies in the deep psychological insight that it offers into the work experiences, both negative (burnout) and positive (work engagement and SOC), of female academics in the rapidly changing South African higher-education institutions. The study contributes to the body of knowledge in the salutogenic paradigm, specifically within a South African context. On a practical note, this article combats the 'leaking-pipeline' scenario, where female academics are lost to the higher-education sector before they reach their full potential.

\section{Burnout}

Maslach and Jackson (1986) originally defined burnout as a syndrome of emotional exhaustion, depersonalisation and reduced personal accomplishment occurring among individuals who do 'people work'. Maslach and her colleagues consequently, however, expanded the burnout concept beyond human services (Maslach \& Leiter, 1997). They therefore redefined burnout as a crisis in one's relationship with work - not necessarily as a crisis in one's relationship with people at work. It became necessary, therefore, to revise and rename the three dimensions to include all jobs and an adapted version of the Maslach Burnout Inventory (MBI) was developed to measure burnout in jobs that are not exclusively human-services jobs, namely the MBI-General Survey. The three dimensions measured by the inventory are exhaustion, cynicism and reduced professional efficacy (Maslach, Jackson \& Leiter, 1996)

Schaufeli (2004) offered a comprehensive definition of burnout, stating that it is a persistent, negative, work-related state of mind in 'normal' individuals that is characterised primarily by exhaustion, which is accompanied by distress, a sense of reduced competence, decreased motivation and the development of dysfunctional attitudes at work.

Within the South African context, Viljoen and Rothmann (2009) found that psychological ill health that could manifest as burnout is a result of complicated work relationships, time pressures, poor learner discipline, a lack of a proper promotion policy, role overload and a lack of resources at Tshwane University of Technology (TUT). Institutional changes required for the transformation from a technikon to a university of technology also have a direct impact on the nature of the work itself.

\section{Work engagement}

Research on the work-engagement concept has taken two separate but related paths (Storm, 2002).

Maslach and Leiter (1997) described work engagement as being characterised by energy, involvement and efficacy, which are considered the direct opposites of the three burnout dimensions, namely exhaustion, cynicism and reduced professional efficacy, respectively. Focusing on work engagement implies a focus on the energy, involvement and effectiveness that employees bring to a job. The authors believe that focus on work engagement builds more effective organisations.

Schaufeli and Enzman (1998) had a slightly different perspective and defined and operationalised work engagement independently from burnout. They considered burnout and work engagement to be opposite concepts that should be measured independently with different instruments.
Schaufeli (2004) consequently defined work engagement as a positive, fulfilling, work-related state of mind that is characterised by vigour, dedication and absorption. Work engagement does not refer to a momentary and specific state but rather to a more persistent and pervasive affectivecognitive state that is not focused on any particular object, event, individual or behaviour.

Rothmann and Jordaan (2006) found that the vigour of South African academics is strongly related to, firstly, growth opportunities in a job and secondly, moderately related to organisational support. With high organisational support, academics are more dedicated, irrespective of the quantity and quality of job demands. Thirdly, advancement opportunities predict work engagement in the sample of academics; they are more likely to invest themselves in their work roles when these resources are present.

\section{Sense of coherence}

The movement towards a positive psychological approach, away from the pathogenic paradigm, led to the development of the sense-of-coherence (SOC) construct by Antonovsky (Antonovsky, 1987; Redelinghuys, 2003; Redelinghuys \& Rothmann, 2004). Antonovsky and Loye (2000) held that humans are able to make sense of their reality despite the increased complexity that they experience. Antonovsky postulated that it is the particular way in which individuals appraise or understand their environment, referred to as SOC, that allows them to make sense of complex environments. SOC is conceptualised as a psychological, global orientation that influences the way in which individuals understand their environments; it can therefore give rise to individual differences in behaviour.

The SOC construct comprises three underlying components, namely comprehensibility, manageability and meaningfulness (Antonovsky, 1987).SOC is conceptualised as a global orientation that expresses the extent to which one has a pervasive, enduring - although dynamic - feeling of coherence manifesting in three behavioural experiences. The first experience refers to stimuli deriving from one's internal and external environments in the course of living being structured, predictable and explicable. This is called comprehensibility, where the individual makes sense of stimuli in the environment. The second experience refers to the belief that resources are available to one to meet the demands posed by these stimuli. This is called manageability, where the individual is able to cope with the demands of the environment. The third experience refers to the belief that these demands are challenges worthy of investment and work engagement. This is called meaningfulness, where the individual is able to identify emotionally and commit effort in handling these demands (Antonovsky, 1987; Du Toit, 2002; Strümpfer, 1990).

Strümpfer and De Bruin (2009) published the results of their meta-analysis of South African data on SOC and job satisfaction (including 32 studies; $N=3446$ ). The strong positive correlation that they found between SOC and job satisfaction (0.50) is consistent with previous research studies, which found that personality variables have a marked effect on job satisfaction.

\section{Integration of the burnout, work-engagement and sense-of-coherence constructs}

According to Schaufeli and Bakker (2001), two dimensions of work engagement are logically related to burnout, namely vigour to exhaustion and dedication to cynicism. Vigour refers to the activation dimension of well-being, while dedication refers to identification with work. Absorption and reduced professional efficacy seem to be less related than the other two dimensions (Rothmann, 2002). According to this framework, burnout is characterised by a combination of exhaustion (low 
activation) and cynicism (low identification), whereas work engagement is characterised by vigour (high activation) and dedication (high identification).

Regarding existing research findings, Schaufeli and Bakker (2001, 2004) extended the job-demands resources model by including work engagement - as measured independently from burnout - and by adding indicators for health impairment and organisational commitment (such as low turnover intention) as possible consequences of burnout and work engagement, respectively. This model is referred to as the comprehensive burnout and work-engagement model. Researchers have consistently found empirical confirmation of the correlation between burnout and work engagement (Hyvönen, Feldt, Salmela-Aro, Kinnunen \& Mäkikangas, 2009).

Van der Collf and Rothmann (2009) studied the correlation between occupational stress, SOC, coping, burnout and work engagement in a sample of nurses in South Africa. Their results indicated that emotional exhaustion is moderately negatively related to work engagement and SOC. Depersonalisation was also moderately negatively related to work engagement and SOC.

The question arises whether a strong SOC can prevent a threat such as burnout (Rothmann, Scholtz, Rothmann \& Fourie, 2002); a person with a strong SOC is indeed likely to see stressful situations as less threatening, which could contribute to lower levels of burnout (Antonovsky \& Sagy, 1985). Feldt (1997) found that, as the level of SOC strengthens, the scores of burnout (specifically emotional exhaustion) decrease. Gilbar (1998) also reported that individuals with a strong SOC experience less burnout than those with a weak SOC. Levert, Lucas and Ortlepp (2000) found that people in the caring professions with a strong SOC and a manageable workload are far less likely to experience emotional exhaustion and depersonalisation; they reported a significant negative correlation between, on the one hand, the two components of burnout of emotional exhaustion and depersonalisation and, on the other hand, SOC.

The negative consequences of burnout, including a deterioration in the quality of service, among many others, have serious consequences for the individual, work group (colleagues), learners (or other care recipients), employer organisations and society as a whole (Golembiewski, Boudreau, Munzenreider \& Luo, 1996; Maslach \& Jackson, 1986).

Research in organisational psychology conducted from a salutogenic paradigm is limited (Strümpfer, 1990), salutogenic functioning referring to those internal driving forces that enable an individual to stay well, succeed and thrive amidst stressful circumstances in life (Rosenbaum, 1990). Aspects such as work engagement and psychological strengths have not yet received the attention that they deserve in academic research (Rothmann, 2002). Indeed, psychology, with its emphasis on human suffering, has been criticised for focusing too much on pathology instead of positive outcomes in the work environment (Diener, Suh, Lucas \& Smith, 1999.) Diener et al. as well as Schaufeli (2004) reported that 17 journal articles have been published on negative constructs, such as stress and conflict, for every journal article published on positive constructs, such as growth and happiness - hence the ratio of 17:1 (positive : negative). In their study, Seligman and Csikszentmihalyi (2000) therefore advocated a drive 'towards a positive psychology'.

A similar trend is observed concerning research on the female gender. Various researchers have, in fact, identified the need for a more positive approach focusing on the enhancement of health in the study of gender differences (Nelson, Burke \& Michie, 2002; Simmons, 2000; Taylor et al., 2000). As long ago as 1994, following their study of occupational stress among university teachers, Blix, Cruise, Mitchell and Blix (1994) reported the need to determine the reason why female academics experience more stress symptoms than their male colleagues.
No studies reporting on the manifestation of burnout, work engagement and SOC in South African institutions of higher education were found. Nor was any study found focusing specifically on the unique experience of the female academic. The objective of this study was therefore to bridge this gap in existing literature and report specifically on the female academic's experience of burnout, work engagement and SOC in institutions of higher education.

The results of this research will contribute towards the growing body of knowledge in positive psychology and towards the salutogenic paradigm. Recommendations for management strategies to facilitate employee work wellness in female academics and suggestions for self-management techniques are offered.

\section{RESEARCH DESIGN}

The aim of this research study was to determine the levels of burnout, work engagement and SOC in female academics at two higher-education institutions in South Africa and to determine whether a relationship exists among these constructs.

\section{Research approach}

A quantitative cross-sectional survey design measuring the variables and reporting on the statistical correlation among them was used (Shaughnessy \& Zechmeister, 1997).

\section{Research method}

The research method followed in this study included the following aspects:

\section{Research participants}

The population consisted of female academics permanently employed at Unisa and TUT. Ethical approval for the study was obtained from the Directorate Human Resources at Unisa and the Faculty Research and Innovation Committee as well as the Ethical Committee at TUT before the measuring instrument was distributed. There were 652 female academics in permanent employment at Unisa and 338 at TUT during this period. The total population of 990 female academics was invited to participate. Of the 990 in the population, 190 responded to the request to participate. Of the questionnaires returned, 187 were usable. The total population that responded was thus $18.9 \%$. Pallant (2001) has argued that, for this type of electronic survey, the minimum number of respondents needed would be $150(15 \%)$. The total of 187 respondents was therefore judged an acceptable response rate.

The biographical variables of the sample were women ranging in age from 32 years to 52 years, with an average of 9.5 years' work experience. Unisa represented $55 \%$ and TUT $45 \%$ of the participants. Of the respondents, $88 \%$ were White, $10 \%$ were Black and $2 \%$ were from the Asian and Coloured groups. Of the respondents, $65 \%$ were married, $19 \%$ were single and $9 \%$ were divorced; the 'living together', 'separated' and 'widowed' categories were significantly smaller. In terms of their highest levels of completed qualifications, $6 \%$ had a national diploma or B degree $(M+3), 27 \%$ had a $B$ technical or honours degree $(M+4)$, $37 \%$ had a masters degree $(M+5)$ and $30 \%$ had a doctoral degree. The majority of the respondents were lecturers or researchers $(41 \%)$, senior lecturers $(23 \%)$ and junior lecturers, researchers or research assistants (12\%). Professors (6\%) and associate professors $(3 \%)$ also represented significant groups within the sample.

\section{Measuring instrument}

The measuring instrument was compiled from a biographical questionnaire, the MBI (to measure the levels of burnout), the Utrecht Work Engagement Scale (UWES) (to measure the levels 
of work engagement) and the SOC questionnaire (to measure the strength of the SOC) of the participants.

The MBI-General Survey consisted of sixteen items that constituted the three sub-dimensions of exhaustion, cynicism and reduced sense of professional efficacy, which were reversescored to make the calculation of a total burnout score possible. All the items were scored on a 7-point frequency rating scale, ranging from 0 (never) to 6 (always) (Maslach \& Jackson, 1981 Maslach \& Jackson, 1986; Maslach \& Leiter, 1997). These subdimensions were regarded as interrelated but conceptually distinct. A total burnout score was calculated by adding the exhaustion, cynicism and reduced professional-efficacy scores.

The UWES consisted of 17 items and was scored on a 7-point frequency rating scale, ranging from 0 ('never') to 6 ('always') (Schaufeli \& Bakker, 2003; Schaufeli \& Enzman, 1998). The three dimensions of the work engagement construct, namely vigour dedication and absorption, were measured by the UWES A total score was calculated by adding the three sub-scores together.

The SOC questionnaire consisted of 29 Likert-type selfrating items (Antonovsky, 1987; Dhaniram \& Cilliers, 2003). The three sub-dimensions of the SOC questionnaire were measured independently, namely, (1) comprehensibility (11 items), (2) manageability (10 items) and (3) meaningfulness (8 items) (Antonovsky, 1987). The scores for comprehensibility, manageability and meaningfulness were added together to compute a total overall score for the SOC construct.

\section{Research procedure}

After ethical approval was obtained from the two institutions, the instrument was sent to all the participants electronically via the internal electronic-communication network of Unisa and TUT. The participants completed the instrument and also returned it electronically to the researcher.

\section{Statistical analysis}

\section{Hypothesis and data processing}

The above discussion led to the following hypothesis formulation:

$\mathbf{H}_{0}$ : There is a significant relationship (correlation) with burnout (as represented by the constructs of exhaustion, cynicism and reduced professional efficacy), work engagement (as represented by the constructs of vigour, dedication and absorption) and SOC (as represented by the constructs of comprehensibility, manageability and meaningfulness) among female academicstaff members at two tertiary institutions in South Africa.

$\mathbf{H}_{1}$ : There is no significant relationship (correlation) with burnout (as represented by the constructs of exhaustion, cynicism and reduced professional efficacy), work engagement (as represented by the constructs of vigour, dedication and absorption) and SOC (as represented by the constructs of comprehensibility, manageability and meaningfulness) among female academic-staff members at two tertiary institutions in South Africa.

The statistical analysis was conducted with the Statistical Package for the Social Sciences (Pallant, 2001).

\section{RESULTS}

\section{Reliability}

Cronbach's alpha was calculated for the sub-dimensions and total scores of the MBI-General Survey, UWES and SOC questionnaire, as provided in Table 1. A Cronbach's alpha of 0.80 is appropriate for cognitive tests, 0.70 is more suitable for ability tests and, for psychological constructs, values below 0.70 can realistically be expected (Field, 2005; Pallant, 2001).
TABLE 1

Cronbach's alpha, means and standard deviations of the Maslach Burnout Inventory, Utrect Work Engagement Scales and Sense of coherence $(N=187)$

\begin{tabular}{lcccc}
\hline Scale & $\boldsymbol{N}$ & Mean & SD & Alpha \\
\hline Burnout & 5 & 14.74 & 7.57 & 0.90 \\
Exhaustion & 5 & 13.33 & 7.36 & 0.81 \\
Cynicism & 6 & 8.72 & 5.34 & 0.68 \\
Reduced professional efficacy & $\mathbf{1 6}$ & $\mathbf{3 6 . 7 9}$ & $\mathbf{1 5 . 9 6}$ & $\mathbf{0 . 8 9}$ \\
Total & & & & \\
& & & & \\
Work engagement & 5 & 4.18 & 1.00 & 0.64 \\
Vigour & 5 & 4.12 & 1.20 & 0.83 \\
Dedication & 6 & 4.19 & 1.03 & 0.75 \\
Absorption & $\mathbf{1 6}$ & $\mathbf{4 . 1 1}$ & $\mathbf{0 . 9 8}$ & $\mathbf{0 . 8 7}$ \\
Total & & & & \\
& & & & \\
Sense of coherence & 11 & 46.43 & 8.55 & 0.65 \\
Coherence & 10 & 47.61 & 8.50 & 0.51 \\
Manageability & 8 & 40.10 & 7.65 & 0.83 \\
Meaningfulness & $\mathbf{2 9}$ & $\mathbf{1 2 8 . 2 2}$ & $\mathbf{1 5 . 3 6}$ & $\mathbf{0 . 9 0}$ \\
\hline Total & & & & \\
\hline
\end{tabular}

$S D$, standard deviation; $N$, number of items

The Cronbach's alpha for the MBI was acceptable (Table 1): reduced professional efficacy was just below 0.70, at 0.68, the deviation being very small. The other Cronbach's alphas were well above 0.70 , ranging from 0.80 to 0.70 .

Regarding the Cronbach's alpha for the UWES, vigour was slightly below the 0.70 mark. The other dimensions scored from 0.75 to 0.87 (Table 2 ).

The Cronbach's alpha for the SOC questionnaire ranged from 0.51 to 0.90 . The Cronbach's alpha for the total SOC questionnaire was 0.9 . The total score was used for the purpose of interpretations in this article.

Based on these results, it was decided to retain burnout and work engagement, with their respective sub-dimensions, and to use the total SOC score.

\section{Validity}

The validity of the three psychometric instruments, namely the MBI, UWES and SOC questionnaire, was investigated with various statistical techniques. Both exploratory and confirmatory factor analyses were performed. To examine the validity of the MBI, UWES and SOC questionnaire, an exploratory factor-analysis method was used to test each of the three scales individually to confirm the validity of the factor structure of each of the scales within the sample.

A rotated pattern matrix was used, which indicated a clearer distribution among the three factors. In this extraction, factor loadings greater than 0.30 were considered as sufficient to assume a strong relationship between a variable and a factor (Pallant, 2001). There were no items with factor loadings less than 0.70 All the items were therefore retained for further analysis.

Factor 1 corresponded with the exhaustion subscale of the MBI and accounted for the most variance $(4.5 \%)$ after the rotation of the factors. Factor 2 accounted for $1.9 \%$ of the total variance and corresponded with the reduced professional-efficacy subscale. Factor 3 accounted for $4.1 \%$ of the total variance and corresponded with the cynicism subscale. A number of items did not correspond with the original sub-dimensions as defined by Maslach and Leiter (1997). After the factor analysis was performed, a score was calculated for each subscale by adding together all the items comprising each subscale to obtain a total score for each. The results of the principal-axis factor analysis supported the three-factor solution found in previous studies, therefore supporting the validity of the scale. 
TABLE 2

Correlation between Maslach Burnout Inventory, Utrect Work Engagement Scales and Sense of coherence

\begin{tabular}{|c|c|c|c|c|c|c|}
\hline & & \multicolumn{4}{|c|}{ Work engagement } & \multirow{2}{*}{$\begin{array}{c}\text { Sense of coherence } \\
\text { Total }\end{array}$} \\
\hline & & Total & Vigour & Dedication & Absorption & \\
\hline \multirow{2}{*}{ Total burnout } & $R$ & -0.72 & -0.68 & -0.75 & -0.53 & -0.48 \\
\hline & $p$ & 0.000 & 0.00 & 0.00 & 0.00 & 0.00 \\
\hline \multirow[t]{2}{*}{ Exhaustion } & $R$ & -0.49 & -0.50 & -0.50 & -0.32 & -0.41 \\
\hline & $p$ & 0.00 & 0.00 & 0.00 & 0.00 & 0.00 \\
\hline \multirow[t]{2}{*}{ Cynicism } & $R$ & -0.66 & -0.57 & -0.70 & -0.51 & -0.41 \\
\hline & $p$ & 0.00 & 0.00 & 0.00 & 0.00 & 0.00 \\
\hline \multirow[t]{2}{*}{ Reduced professional efficacy } & $R$ & -0.55 & -0.54 & -0.56 & -0.43 & -0.30 \\
\hline & $p$ & 0.00 & 0.00 & 0.00 & 0.00 & 0.00 \\
\hline \multirow[t]{2}{*}{ Total work engagement } & $R$ & 1.00 & 0.89 & 0.94 & 0.91 & 0.52 \\
\hline & $p$ & - & 0.00 & 0.00 & 0.00 & 0.00 \\
\hline \multirow[t]{2}{*}{ Vigour } & $R$ & - & 1.00 & 0.78 & 0.71 & 0.46 \\
\hline & $p$ & - & - & 0.00 & 0.00 & 0.00 \\
\hline \multirow[t]{2}{*}{ Dedication } & $R$ & - & - & 1.00 & 0.76 & 0.52 \\
\hline & $p$ & - & - & - & 0.00 & 0.00 \\
\hline \multirow[t]{2}{*}{ Absorption } & $R$ & - & - & - & 1.00 & 0.45 \\
\hline & $p$ & - & - & - & - & 0.00 \\
\hline
\end{tabular}

Regarding the factor structure of the UWES, a rotated pattern matrix was also performed. There were no items with factor loadings less than 0.3 and all the items were therefore retained for further analysis. Although three clear factors emerged, as suggested by the theory, these items did not correspond perfectly with the items defined by Schaufeli and Bakker (2003) as belonging to each of the questionnaire sub-dimensions. Factor 1 had the most items loading on the scale and accounted for the most variance $(6 \%)$ after the rotation of the factors. Factor 2, which also had a number of strong items loading on it, accounted for $3 \%$ of the total variance. Factor 3 accounted for $4 \%$ of the variance.

A rotated pattern matrix was performed for the SOC questionnaire, which indicated that three items had factor loadings less than 0.30 (Items $0.30,3.13$ and 3.10). Factor 1 corresponded with the comprehensibility subscale of SOC and accounted for the most variance $(4.4 \%)$ after the rotation of the factors. Factor 2 accounted for $3.8 \%$ of the total variance and corresponded with the meaningfulness subscale. Factor 3 accounted for $3 \%$ of the total variance and corresponded with the manageability subscale. A number of items did not correspond with the three sub-dimensions identified by Antonovsky (1987).

Principal-axis factor analysis with a direct oblimin rotation was used to investigate whether the factor structures of the three instruments could be replicated according to theoretical analysis. Prior to performing the factor analysis, the suitability of the data for factor analysis was assessed. The correlation matrices of each of the three instruments revealed a number of coefficients of 0.30 and above. The Kaiser-Mayer-Oklin value of each instrument exceeded the recommended value of 0.60 (Pallant, 2001) $(\mathrm{MBI}=0.84$; UWES $=0.93$; SOC $=0.81$ ). The Bartlett's Test of Sphericity was statistically significant $(p=0.000)$, the sample size being greater than the recommended 150 respondents $(n=187)$ (Pallant, 2001). The data were therefore considered suitable for factor analysis.

After the exploratory analysis, a confirmatory factor analysis was also performed on the MBI-General Survey, the UWES and the SOC questionnaire. Confirmatory factor analysis seeks to determine if the number of factors and the loadings of measured (indicator) variables on them conform to what is expected on the basis of pre-established theory (Garson,
1998) The Root Mean Square Error of Approximation, Hoelter Index, Bentler Bonett Index and Tucker Lewis Index were used to determine goodness-of-fit. The Root Mean Square Error of Approximation presented moderate support for the MBI model. The Hoelter Index, Bentler Bonett Index and Tucker Lewis Index did not indicate goodness-of-fit for the MBI model. All goodness-of-fit indicators for the UWES were found to be poor. Caution should therefore be exercised in the interpretation of the sub-dimensions of the work-engagement scores. The Root Mean Square Error of Approximation presented moderate support for the SOC model (Antonovsky, 1987). The Hoelter Index, Bentler Bonett Index and Tucker Lewis Index failed to provide proof of goodness-of-fit for this model.

\section{Correlation analysis}

Table 2 provides a summary of the correlation analysis results. The relationship for the total scores for the MBI (burnout), UWES (work engagement) and SOC questionnaire (SOC) are highlighted.

Strong support was found for the hypothesis. Significant correlations among burnout, work engagement and SOC, as the results of the Pearson's correlation matrix, were revealed for all

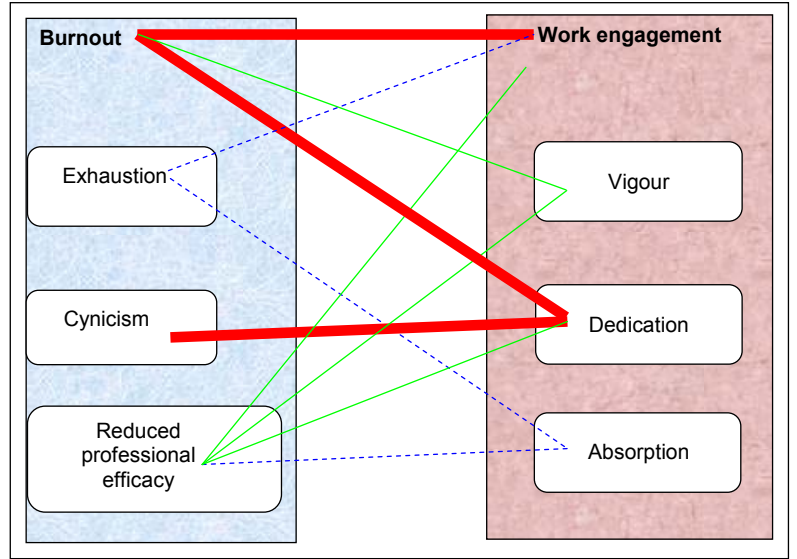

FIGURE 1

Representation of significant correlations between burnout and work engagement 


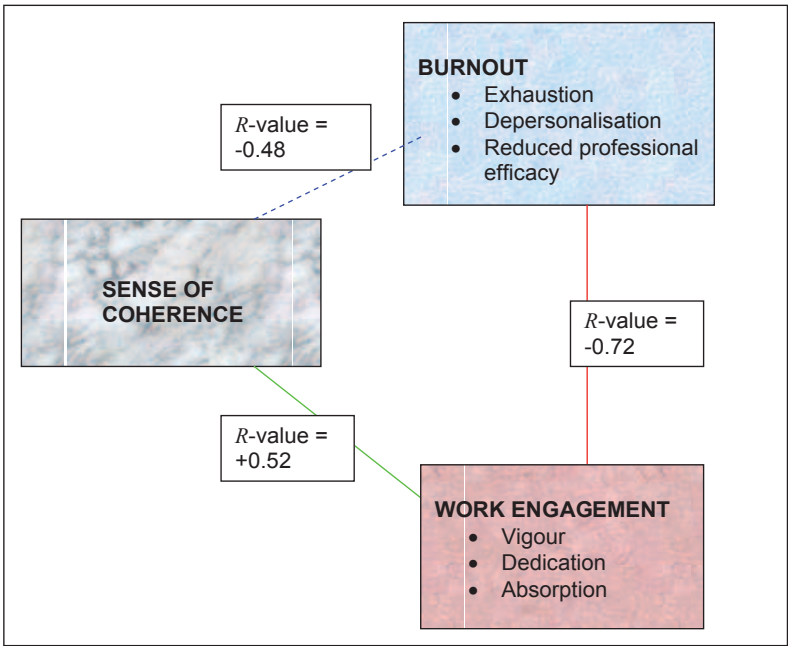

FIGURE 2

Representation of significant correlations with burnout, work engagement and sense of coherence

the total scores of the MBI, UWES and SOC questionnaire, as represented in Figure 1.

The correlations among the different sub-dimensions of the MBI and the UWES are provided in Figure 2. From the empirical investigation, it is evident that several significant correlations were manifested (Bezuidenhout, 2009).

\section{Regression analysis}

The results of the regression analysis are presented in Tables 3 and 4 .

Table 4 shows that $60 \%$ of burnout can be explained by SOC and work engagement. Three of the work engagement subdimensions were found to be significant predictors of burnout, the dedication $(\beta=0.59 ; t=6.78 ; p=0.000)$, vigour $(\beta=0.27 ; t=$ $3.46 ; t=0.001)$ and absorption $(\beta=0.19 ; t=2.5 ; t=0.013) \mathrm{sub}-$ dimensions together accounting for $60 \%$ of variance in burnout. Van der Colff and Rothmann (2009) found in their study that SOC could predict emotional exhaustion (a sub-dimension of burnout). The remaining sub-dimensions did not contribute significantly to the burnout model.

\section{DISCUSSION}

Previous studies predominantly concentrated on the negative consequences of burnout. This study, however, confirms

\begin{tabular}{|c|c|c|c|c|c|c|}
\hline \multirow[t]{2}{*}{ Model } & \multirow[t]{2}{*}{$R$} & \multirow[t]{2}{*}{$R^{2}$} & \multirow{2}{*}{$\begin{array}{c}\text { Adjusted } \\
R^{2}\end{array}$} & \multirow{2}{*}{$\begin{array}{c}S E \\
\text { of the estimate }\end{array}$} & \multicolumn{2}{|c|}{ Anova } \\
\hline & & & & & $F$ & $p$ \\
\hline \multirow{2}{*}{\multicolumn{7}{|c|}{$\begin{array}{l}\text { Predictors: } \\
\text { (Constant) }\end{array}$}} \\
\hline & & & & & & \\
\hline Dedication & 0.781 (d) & 0.610 & 0.602 & 10.07 & 71.2 & 0.000 \\
\hline Vigour & 0.781 (d) & 0.610 & 0.602 & 10.07 & 71.2 & 0.000 \\
\hline Absorption & 0.781 (d) & 0.610 & 0.602 & 10.07 & 71.2 & 0.000 \\
\hline
\end{tabular}

SE, standard error

TABLE 4

Regression coefficients of regression equation to predict burnout

\begin{tabular}{lccccccc}
\hline Model & \multicolumn{2}{c}{$\begin{array}{c}\text { Unstandardised } \\
\text { coefficients }\end{array}$} & & \multicolumn{2}{c}{$\begin{array}{c}\text { Standardised } \\
\text { coefficients }\end{array}$} & & \\
\cline { 2 - 3 } & $\boldsymbol{B}$ & $\boldsymbol{S E}$ & & Beta & & \multicolumn{1}{c}{ Sig. } \\
\hline (Constant) & 86.827 & 4.309 & & - & & 20.151 & 0.000 \\
$\mathrm{De}$ & -1.567 & 0.231 & & -0.593 & & -6.778 & 0.000 \\
$\mathrm{Vi}$ & -0.859 & 0.249 & & -0.269 & & -3.455 & 0.001 \\
$\mathrm{Ab}$ & 0.486 & 0.193 & & 0.187 & & 2.514 & 0.013 \\
\hline
\end{tabular}

a significant empirical relationship with burnout, work engagement and SOC in female academics. The practical implications of these findings, specifically from a positive psychological paradigm, are elucidated in this discussion.

In terms of burnout levels, the sample manifested with average levels of exhaustion, coupled with strong indications of increased cynicism and moderate indications of a decrease in a sense of professional efficacy. The typical female academic therefore experiences average levels of physical, emotional and mental exhaustion, associated with average feelings of being tired, 'drained' and 'used up'. The job-demands resources model posits that job demands are associated with exhaustion, whereas a lack of job resources is associated with cynicism and disengagement with the job (Demerouti, Bakker, Nachreiner \& Schaufeli, 2001). Reduced professional efficacy is also believed to develop as a result of the absence of necessary job resources. It is deduced that both unreasonably high job demands and an absence of job resources manifest as contributors to burnout in female academics.

The typical female academic in this study presents with high levels of cynicism, implying negative, detached feelings towards, for example, students, colleagues and work in general. This is a warning sign that should not be overlooked by health professionals and the management of tertiary institutions in South Africa. In the phase model of burnout proposed by Golembiewski and Munzenrider (1988), cynicism (depersonalisation in the original MBI) initiates the burnout process. The female academics' high score on cynicism in this study highlights the interpersonal dimension of burnout and indicates a negative, callous and detached response to various other aspects of the job.

The phase model of burnout maintains that depersonalisation is initially experienced because a certain degree of professional detachment is often functional in dealing with others in a more 'objective' manner (Golembiewski et al., 1996; Golembiewski \& Munzenrider, 1988). Because of the demands incurred through increased class sizes, an increased need for personal guidance from students and escalating interpersonal contact and communication, female academics are relying heavily on this state of 'professional detachment' to protect themselves from feelings of depletion. Detachment, however, becomes depersonalisation or cynicism, impairing the ability to develop personal relationships (Basson, 2002). The particularly high degree of cynicism present is an indication that the next phase in which the development of personal relationships is impaired will become a problem in this target group of female academics. The inability to develop and maintain interpersonal relationships leads to impaired coping, as social support from colleagues, friends and family members is not optimally utilised when interpersonal relationships are strained. This is an indication that female academics will probably develop more advanced stages of burnout.

As the score for reduced professional efficiency of the female academics shows a somewhat increased tendency, it is noteworthy that their self-appraisal in terms of their own ability to cope with the demands of their jobs shows negative signs. As the sense of professional efficacy is reduced, selfevaluation becomes more negative and feelings of competence, productivity and achievement at work dwindle (Fourie, 2005). As burnout in its early stages is often overlooked or mistaken for simple 'tiredness', it is possible that the signs of burnout that are manifested (as cynicism and reduced professional efficacy) could also be overlooked or ignored in this target group.

In terms of the manifestation of work engagement in the sample of female academics measured against the norms provided by Schaufeli and Bakker (2003), the scores for total work engagement, vigour, dedication and absorption are all just above average, indicating a positive trend. The female academics are thus generally fairly energetic, mentally resilient, 
strongly involved in their jobs, enthusiastic, proud, inspired and happily engrossed in their work. Compared with a group of Dutch managers (Schaufeli \& Bakker, 2004), these scores are fairly high, with the exception of absorption (which is a little lower). The manifestation of work engagement in the female academics is, however, marginally lower than the scores for the physicians in the Dutch database but the scores for the female academics are notably higher than the scores for the international police force.

Schaufeli and Bakker (2001) noted that work engagement, specifically vigour, is characterised by mental resilience and the willingness to invest effort in one's work, even in the face of difficulty. This could explain why work engagement is manifested in the female academics studied, even though there are definite signs of burnout (increased cynicism and reduced professional efficacy). The female academics therefore invest effort in their work, even though they experience difficulties in the fulfilment of these duties. These difficulties include decreasing resources to get work done and increasing demands by faculty, students and parents. They often take the form of increased lecturer-student ratios, increased demand for research outputs, exhausting interpersonal relationships with students and escalating administrative duties. The role of mergers, restructuring, unilateral changes in work conditions and the resulting lack of promotional opportunities also has a negative effect on the wellness of the target group.

Based on the results, it is clear that there is not a perfectly negative correlation between burnout and work engagement (or their respective sub-dimensions). The conviction of Schaufeli and Bakker $(2001,2004)$ that burnout and work engagement should be measured independently as separate but related constructs (referred to as the comprehensive burnout and workengagement model) is therefore confirmed in this target group.

As this study is undertaken from a salutogenic paradigm, it is noteworthy that, from a positive psychological point of view, burnout is redefined as an erosion of work engagement with the job (Maslach \& Leiter, 1997). What starts out as important, meaningful and challenging work becomes unpleasant, unfulfilling and meaningless. Energy turns into exhaustion, involvement turns into cynicism and efficacy turns into reduced professional efficacy. This could contribute to the 'leaking pipeline'.

From a preventative point of view, the danger exists that, if burnout symptoms are not managed effectively and contained, academic work that is viewed as important, meaningful and challenging could soon become unpleasant to the women in this study. They could start to experience it as unfulfilling and meaningless. From the empirical study, it was already established that, in this sample, involvement has turned into cynicism, with associated negative symptoms.

In terms of the total score for SOC, the target group scored 128.22 , which is lower than the estimate of the mean value for SOC (i.e. 137) as calculated by Strümpfer and Wissing (1998). When compared to another all-women South African sample consisting of working mothers (Herbst, 2006), the score is also lower than the 134.26 scored by the working mothers.

A good load balance, that is an under-overload balance in life experience, provides the manageability component. Underload refers to there not being enough direction or to individuals seldom being called upon to exercise their abilities or to actualise their potential. Overload refers to individuals setting a pace too rapid for demanded development or to never having enough time and energy to do everything or not having enough resources to do everything. The question is therefore whether the female academics perceive the resources at their disposal as adequate to meet the demands posed by stimuli (Antonovsky, 1987; De Wet, 1998). Based on the empirical evidence from the
MBI-General Survey, the answer is probably not, which, in turn, has a negative effect on the manageability component of SOC.

Strong support was found for the existence of a significant relationship with burnout, work engagement and SOC in female academics. The empirical study also revealed significant relationships between the total scores and the sub-dimensions of the MBI, UWES and SOC questionnaire. Burnout and work engagement as well as burnout and SOC were found to be negatively correlated. SOC, however, was found to be positively correlated with the experience of work engagement. The implication is that a strong SOC does indeed act as a buffer against the development of the pathogenic state of burnout. The opposite, however, is also true, in that female academics with a low SOC are vulnerable to the development of burnout (exhaustion, cynicism and a feeling of reduced professional efficacy). A strong SOC helps employees to understand stressors and to regard them as manageable and meaningful. A strong SOC therefore moderates the effects of job stressors on exhaustion and contributes to the perception of the professional efficacy of employees (Ortlepp, 1998; Steyn, Rothmann \& Mostert, 2004). Testing whether work engagement is positively correlated with SOC also received strong support, as the total scores and sub-dimensions of the UWES and SOC questionnaire were found to be positively correlated with each other. Female academics with a SOC are thus much more likely to experience work engagement. This implies feelings of energy, resilience, persistence, enthusiasm and inspiration.

From the empirical results, the strength of the correlation between SOC and cynicism, a sub-dimension of burnout, draws attention. This is of specific importance to this study, as the population group scored particularly high on the cynicism sub-dimension of burnout. The question invariably arises whether this has to do with the respondents failing to find meaning in their jobs. As previously explained, respondents with high cynicism levels are expected to 'depersonalise' relationships with their care recipients and colleagues. The result of such a process is that female academics, for example, experience a breakdown in their relationships with their students and colleagues. They start to expect the worse from these relationships and, in an effort to protect themselves from further emotional exhaustion, reduce personal contact between themselves and their students and colleagues to the bare minimum.

Van Emmerik (2002) found that assistance from colleagues and a supportive departmental climate, together with practical assistance, reduces exhaustion in academics. Practical assistance in the form of flexitime is specifically successful for female academics. Avoiding such assistance is thus not a useful or desirable strategy.

Barkhuizen et al. (2004) also noted increased levels of exhaustion and cynicism in their study of burnout in academics in South Africa. They attributed this trend to a decrease in resources, including unfair rewards, poor management, poor social support and a lack of participation, which, in turn, contributes to the experience of a reduction in professional efficacy. The result of this isolation is that female academics are unfortunately also cut off from the emotional or other support that could be forthcoming from these interpersonal relationships. This, in itself, has the potential to form a negative spiral, in that loss of meaning leads to cynicism and isolation, which then contributes to a loss in sense of meaning.

From the above, it is evident that there is a strong negative correlation between SOC and work engagement. Again, the SOC construct of meaningfulness plays a central role. Strong negative relationships between meaningfulness (SOC) and total work engagement as well as the work engagement constructs of vigour and dedication can be observed. It is evident that being able to find meaning in their jobs plays a very important 
role in female academics' ability to achieve work engagement (specifically vigour and dedication). Although slightly less pronounced, significant relationships among all three SOC dimensions and all three work-engagement dimensions are also present. Antonovsky (1987) was convinced that a person with a high SOC is more likely to define stimuli as non-stressors and to define stress attributed to stimuli perceived as stressors as benign or irrelevant.

A strong negative correlation was found between the total scores for burnout and work engagement. Cynicism reflects indifference or a distant attitude towards work. This refers more to the work itself rather than to personal relationships at work. It is seen as a negative, callous or detached response to various aspects of the job. It is specifically used for jobs where there is no constant interpersonal interaction between burntout employees and their subjects (recipients), as would be the case with nurses and their patients.

Another very strong negative correlation that manifests itself is the negative relationship between cynicism and dedication. As the female academics in this target group scored very high on cynicism, the obvious conclusion is that their dedication to the academic jobs that they are performing is on the decline. The timely introduction of flexitime and practical assistance from academic departments, as advocated by Van Emmerik (2002), could combat cynicism and decline in dedication in female academics.

It is noteworthy that the correlation between burnout and work engagement (although very strong) is not absolute, confirming the theoretical model of Schaufeli and Bakker (2003) that burnout and work engagement are negatively correlated but are not the exact opposites of each other. It is theoretically possible for an academic to feel burnt-out but still experience the vigour, dedication and absorption that characterise work engagement. It is, for example, possible that academics experience feelings of burnout when they lecture to large groups but still become totally engrossed in other aspects of their jobs, such as research The reason for this is that work engagement is defined as mental resilience and the willingness to invest effort in one's work, even in the face of difficulty. Resilience is thus an important aspect in the manifestation of work engagement.

A regression analysis was performed on the data. Based on the literature study, it was decided to perform a regression analysis on burnout. The dedication, vigour, absorption (work engagement) and meaningfulness (SOC) sub-dimensions together accounted for $60 \%$ of the variance in burnout. The remaining sub-dimensions did not contribute significantly to the burnout model.

The implication of this finding is that the dedication, vigour and absorption sub-dimensions of work engagement as well as the meaningfulness subscale of SOC can predict $60 \%$ of the variance in the burnout levels in female academics. The comprehensibility and manageability sub-dimensions of SOC did not feature significantly in predicting the occurrence of burnout. From these results, it can be deducted that the meaningfulness subscale of SOC plays a very important role in moderating burnout levels. It is noteworthy that the emotional element of SOC (meaningfulness) again plays a significant role. As Feldt (1997) explained, people with a strong SOC are more likely to define stressors as welcome challenges and to feel confident that they can handle these well.

\section{Limitations of the study}

Studies on the manifestation of and the relationship among burnout, work engagement and SOC, specifically in females, are very scarce. The second construct, namely work engagement, together with its measuring instrument, the UWES, is a recently developed construct, which made it challenging to find information and existing research results (both locally and internationally) on the construct.
The fact that a cross-sectional design was used creates a limitation in terms of the solving of cause-and-effect issues. It is therefore recommended that longitudinal research be done in future to investigate these aspects. The relatively small sample size (187 respondents) also implies that caution should be exercised when generalising to the general population of female academics in South Africa.

\section{Recommendations for future research}

It is strongly recommended that female academics in other institutions in different geographical areas in South Africa also be studied to confirm the research results. A larger sample size and additional biographical criteria (such as number of dependants, care-giving responsibilities and primary breadwinner role) will add value to the body of salutogenic knowledge available on the work experience of female academics in the current South African context. The impact of the rapidly changing South African higher-education landscape, including the influence of mergers, forced transfers and redundancies on female academics, should also receive scholarly attention (Bezuidenhout \& Cilliers, 2009).

\section{Conclusion}

UNESCO (2009) and De la Rey (2008) noted that research studies specifically on female academics are limited. The purpose of this study was therefore to determine the levels of burnout, work engagement and SOC in female academics in South Africa and whether a significant correlation exists among these constructs. This research study empirically measured and described the levels of burnout, work engagement and SOC as well as the significant correlations among these constructs. Higher-education institutions that want to find a solution to the 'leaking-pipeline' syndrome of their female academics will benefit from the practical recommendations made in this article.

\section{REFERENCES}

Antonovsky, A. (1987). Unravelling the mystery of health: How people manage stress and stay well. San Francisco: Jossey-Bass.

Antonovsky, H., \& Sagy, S. (1985). The development of a sense of coherence and its impact on responses to stress situations. The Journal of Social Psychology, 126, 213-255.

Barkhuizen, E.N., Rothmann, S., \& Tytherleigh, M.Y. (2004 March). Burnout of academic staff in an HEI. Paper presented at the 2nd South African Work Wellness Conference, Potchefstroom, South Africa.

Basson, M.J. (2002). Sense of coherence, coping and burnout of pharmacists in a corporate pharmacy group. Unpublished master's thesis, Potchefstroom University for Christian Higher Education Please insert after this (now North West University), South Africa.

Bezuidenhout, A. (2009). Burnout, work engagement and sense of coherence in female academics at two tertiary institutions in South Africa. Unpublished doctoral dissertation, University of South Africa, Pretoria, South Africa.

Bezuidenhout, A., \& Cilliers, F.V.N. (2009, October). The journey from burnout to work engagement for female academics: $A$ challenge for merged institutions of higher education. Paper presented at the Higher Education Merger Conference, Pretoria, South Africa.

Blix, A.G., Cruise, C.J., Mitchell, B.M., \& Blix, G.G. (1994) Occupational stress among university teachers. Educational Research, 36, 157-169.

Burke, R.J., \& Greenglass, E. (1995). A longitudinal examination of the Cherniss model of psychological burnout. Social Science and Medicine: An International Journal, 40(10), 1357-1363.

De la Rey, C. (2008, March). Women in higher education: The leaking pipeline. Retrieved September 11, 2009 from http:// blogs.uct.ac.za/blog/transformation-agenda/2008/03/31/ women-in-higher-education-the-leaking-pipeline. 
Demerouti, E., Bakker, A.B., Nachreiner, F., \& Schaufeli, W.B. (2001). The job-demands-resources model of burnout. Journal of Applied Psychology, 86, 499-512.

De Wet, C.F. (1998). A salutogenic perspective of burnout in the nursing profession. Unpublished doctoral dissertation. University of South Africa, Pretoria.

Dhaniram, N., \& Cilliers, F. (2003). Stress, burnout and salutogenic functioning amongst community service doctors in KwaZuluNatal hospitals. Unpublished master's thesis, University of South Africa, Pretoria, South Africa.

Diener, E., Suh, E.M., Lucas, R.E., \& Smith, H.I. (1999). Subjective well being: Three decades of progress. Psychological Bulletin, $125,267-302$

Du Toit, F.S. (2002). The relationship between sense of coherence, learned resourcefulness and personality type among technical personnel. Unpublished master's thesis, University of South Africa, Pretoria, South Africa.

Feldt, T. (1997). The role of sense of coherence in well-being at work: Analysis of main and moderator effects. Work and Stress, 11, 134-147.

Field, A. (2005). Discovering statistics using SPSS. London: Sage.

Fourie, J.C.J. (2005). The relationship between burnout and personality types at middle management level. Unpublished master's thesis. Pretoria: University of South Africa.

Garson, G.D. (1998). Factor analysis: Stat notes, from North Carolina State University, Public Administration Program. Retrieved November 11, 2007, from http://www2.chass.ncsu.edu/ garson/pa765/factor.htm.

Gilbar, O. (1998). Relationship between burnout and sense of coherence. Social Work in Health Care, 26(3), 39-49.

Golembiewski, R.T., Boudreau, R.A., Munzenrider, R.F. \& Luo, H. (1996). Global burnout: A worldwide pandemic explored by the phase model. Greenwich, CT: JAI Press.

Golembiewski, R.T. \& Munzenrider, R.F. (1988). Phases of burnout: Developments in concepts and applications. New York: Praeger.

Herbst, A.W. (2006). Personality, coping and sense of coherence of the working mother. Unpublished master's thesis, University of South Africa, Pretoria, South Africa.

Hyvönen, K., Feldt, T., Salmela-Aro, K., Kinnunen, U., \& Mäkikangas, A. (2009). Young managers' drive to thrive: A personal work goal approach to burnout and work engagement. Journal of Vocational Behaviour, 75(2), 183196.

Lease, S.H. (1999). Occupational role stressors, coping, support, and hardiness as predictors of strain in academic faculty: An emphasis on new and female faculty. Research in Higher Education, 40(3), 1999.

Levert, T., Lucas, M., \& Ortlepp, K. (2000). Burnout in psychiatric nurses: Contributions of the work environment and a sense of coherence. South African Journal of Psychology, 30(2), 3643.

Loye, D. (2000). An arrow through chaos: How we see into the future. Rochester, VT: Park Street Press.

Maslach, C., \& Jackson, S. (1981). The measurement of experienced burnout. Journal of Occupational Behaviour, 2, 99-113.

Maslach, C., \& Jackson, S. (1986). MBI: Maslach burnout inventory: Manual research edition. Palo Alto, CA: Consulting Psychologists Press.

Maslach, C., Jackson, S.E., \& Leiter, M.P. (1996). Maslach burnout inventory manual. (3rd edn.). Palo Alto, CA: Consulting Psychologists Press.

Maslach, C., \& Leiter, M.P. (1997). The truth about burnout. San Francisco: Wiley.

Nelson, D.L., \& Simmons, B.L. (2005). In A.S.G. Antoniou \& C.L. Cooper (Ed.), Research companion to organisational health psychology (pp. 500-515). Northhampton: Elgar.

Ortlepp, K. (1998). Non-professional trauma debriefers in the workplace: Individual and organisational antecedents and consequences of their experiences. Unpublished doctoral dissertation, University of the Witwatersrand, Johannesburg, South Africa.
Pallant, J. (2001). SPSS survival manual. 2001. New York: McGrawHill.

Redelinghuys, F.J. (2003). Koherensiesin, coping, uitbranding en begeestering in die bediening [Sense of coherence, coping, burnout and engagement in the ministry]. Unpublished master's thesis, Potchefstroom University for Christian Higher Education Please insert after this (now North West University), South Africa.

Redelinghuys, F.J., \& Rothmann, S. (2004, March). Koherensiesin, coping, uitbranding en begeestering in die bediening [Sense of coherence, coping, burnout and engagement in the ministry]. Paper presented at the 2nd South African Work Wellness Conference, Potchefstroom, South Africa.

Rosenbaum, M. (1990). Learned resourcefulness: On coping skills, self-control and adaptive behaviour. New York: Springer.

Rothmann, S. (2002, November). Burnout and engagement: A fortigenic perspective. Inaugural lecture, Potchefstroom University for Christian Higher Education, Potchefstroom, South Africa.

Rothmann, S., \& Jordaan, G.M.E. (2006). Job demands, job resources and work engagement of academic staff in South African Higher Education Institutions. South African Journal of Industrial Psychology, 32(4), 87-96.

Rothmann, S., Scholtz, P.E., Rothmann, J.C., \& Fourie, M. (2002, June). The relationship between individual variables and work-related outcomes. Paper presented at the 47th World Conference for Small Business, San Juan, Puerto Rico.

Schaufeli, W.B. (2004, March). Burnout and engagement. Paper presented at the 2nd South African Work Wellness Conference, Potchefstroom, South Africa.

Schaufeli, W.B. \& Bakker, A.B. (2001). Job demands, job resources and their relationship with burnout and engagement: A multisample study on the COBE-model. Utrecht University: Psychology \& Health.

Schaufeli, W., \& Bakker, A. (2003). Utrecht work engagement scale: Preliminary manual. Utrecht: Utrecht University.

Schaufeli, W.B., \& Bakker, A.B. (2004). Job demands, job resources and their relationship with burnout and engagement: A multi-sample study. Journal of Organisational Behaviour, 25, 293-315.

Schaufeli, W.B., \& Enzman, D. (1998). The burnout companion to study and practice: A critical analysis. London: Taylor \& Francis.

Seligman, M.E.P., \& Csikszentmihalyi, M. (2000). Positive psychology: An introduction. American Psychologist, 55, 5-14.

Shaughnessy, J.J., \& Zechmeister, E.B. (1997). Research methods in psychology. (4th edn.). New York: McGrawHill.

Simmons, B.L. (2000). Eustress at work: Accentuating the positive. Unpublished doctoral dissertation, Oklahoma State University, Oklahoma City.

Steyn, L.J., Rothmann, S., \& Mostert, K. (2004, March). Sense of coherence, coping and burnout in an electricity supply organization. Paper presented at the 2nd South African Work Wellness Conference Please insert after this (now North West University), South Africa.

Storm, K. (2002). Burnout and work engagement in the South African Police Service. Unpublished doctoral dissertation, North-West University, Potchefstroom, South Africa.

Strümpfer, D.J.W. (1990). Salutogenesis: A new paradigm. South African Journal of Psychology, 20, 265-276.

Strümpfer, D.J.W., \& De Bruin, G.P. (2009). Antonovsky's sense of coherence and job-satisfaction: Meta-analysis of South African data. South African Journal of Industrial Psychology/ Suid-Afrikaanse Tydskrif vir Bedryfsielkunde, 35(1), Art.\#767, 3 pages. DOI: 10.4102/sajip.v35i1.767. 
Strümpfer, D.J.W., \& Wissing, M.P. (1998, September). Review of South African data on the SOC scale as a measure of fortigenesis and salutogenisis. Article distributed at the PsySSA Congress, Cape Town, South Africa.

Taylor, S.E., Klein, L.C., Lewis, B.P., Grunewald, T.L., Gurung, R.A., \& Updegraff, J.A. (2000). Bio-behavioural responses to stress in females: Tend-and-befriend, not fight-or-flight. Psychological Review, 107, 411-429.

Tytherleigh, M.Y. (2003). What employers may learn from English HEIs: A fortigenic approach to occupational stress. South African Journal of Industrial Psychology, 29(4), 101106.

UNESCO vide United Nations Educational, Scientific and Cultural Organisation. (2009). Retrieved October 18, 2009, from http://www.unesco.org/en/wche2009/sub-themes/ equity-access-and-quality/

Van den Broeck, A., Vansteenkiste, M., De Witte, H., \& Lens, W. (2008). Explaining the relationship between job characteristics, burnout, and engagement: The role of basic psychological need satisfaction. Work and Stress, 22(3), 277294.
Van der Colff, J.J., \& Rothmann, S. (2009). Occupational stress, sense of coherence, coping, burnout and work engagement of registered nurses in South Africa. South African Journal of Industrial Psychology/Suid-Afrikaanse Tydskrif vir Bedrufsielkunde, 35(1), Art.\#423, 10 pages. DOI: 10.4102/sajip. v35i1.423.

Van Emmerik, I.J.H. (2002). Gender differences in the effects of coping assistance on the reduction of burnout in academic staff. Work and Stress, 16(3), 251-263.

Van Tonder, C.L., \& Williams, C. (2009). Exploring the origins of burnout among secondary educators. South African Journal of Industrial Psychology/Suid-Afrikaanse Tydskrif vir Bedryfsielkunde, 35(1), Art.\#762, 15 pages. DOI: 10.4102/sajip. v35i1.762.

Viljoen, P.J., \& Rothmann, S. (2009). Occupational stress, ill health and organizational commitment of employees at a university of technology. South African Journal of Industrial Psychology/Suid-Afrikaanse Tydskrif vir Bedryfsielkunde, 35(1), Art.\#730, 11 pages. DOI: 10.4102/sajip.v35i1.7300.4102/sajip. v35il.762. 